How to cite this paper:

Nur Azriati Mat, Aida Mauziah Benjamin \& Syariza Abdul-Rahman (2018). Enhanced heuristic algorithms with a vehicle travel speed model for time-dependent vehicle routing: A waste collection problem. Journal of Information and Communication Technology (JICT), 17 (1), 55-78.

\title{
ENHANCED HEURISTIC ALGORITHMS WITH A VEHICLE TRAVEL SPEED MODEL FOR TIME-DEPENDENT VEHICLE ROUTING: A WASTE COLLECTION PROBLEM
}

\author{
Nur Azriati Mat, Aida Mauziah Benjamin \& Syariza Abdul-Rahman \\ Institute of Strategic Industrial Decision Modelling, \\ School of Quantitative Sciences,Universiti Utara Malaysia, Malaysia \\ nur_azriati@ahsgs.uum.edu.my; mauziah@uum.edu.my; syariza@uum.edu.my
}

\begin{abstract}
This paper proposes a vehicle travel speed model to enhance two heuristic algoritihms from previous studies, namely current initial solution (CIS) and different initial customer (DIC). Both algorithms are used to solve a real-life waste collection vehicle routing benchmark problem with dynamic travel speeds. This problem is referred to as Time-Dependent Vehicle Routing Problem (TD-VRP) in previous literature. The benchmark problem consisted of ten sub problems, involving up to 2092 customers. Previous studies solved the benchmark problem using DIC and CIS algorithms with the assumption that the vehicles are travelling with a static speed when collecting the waste. However, in this paper the static speed that was considered in both algorithms were improved by introducing dynamic travel speeds to construct vehicle routes for the waste collection drivers. Compared to previous studies the enhanced CIS and DIC with dynamic travel speeds affected the waste collection problem in terms of the number of vehicles used, the total distance travelled and the total travel time. However, different settings of speed may give different impacts to the solution. The study reveals that with a setting of dynamic speed between $40 \mathrm{mph}$ and $55 \mathrm{mph}$, DIC is able to reduce two vehicles (from 98 to 96 number of vehicles used), $7.85 \%$ of total distance travelled, and $19.10 \%$ of total travel time.
\end{abstract}

Keywords: Time-dependent vehicle routing, dynamic travel speed, waste collection, heuristics. 


\title{
ENHANCED HEURISTIC ALGORITHMS WITH A VEHICLE TRAVEL SPEED MODEL FOR TIME-DEPENDENT VEHICLE ROUTING: A WASTE COLLECTION PROBLEM
}

\author{
Nur Azriati Mat, Aida Mauziah Benjamin \& Syariza Abdul-Rahman \\ Institute of Strategic Industrial Decision Modelling, \\ School of Quantitative Sciences, Universiti Utara Malaysia, Malaysia
}

\author{
nur_azriati@ahsgs.uum.edu.my;mauziah@uum.edu.my; \\ syariza@uum.edu.my
}

\begin{abstract}
This paper proposes a vehicle travel speed model to enhance two heuristic algoritihms from previous studies, namely current initial solution (CIS) and different initial customer (DIC). Both algorithms are used to solve a real-life waste collection vehicle routing benchmark problem with dynamic travel speeds. This problem is referred to as Time-Dependent Vehicle Routing Problem (TD-VRP) in previous literature. The benchmark problem consisted of ten sub problems, involving up to 2092 customers. Previous studies solved the benchmark problem using DIC and CIS algorithms with the assumption that the vehicles are travelling with a static speed when collecting the waste. However, in this paper the static speed that was considered in both algorithms were improved by introducing dynamic travel speeds to construct vehicle routes for the waste collection drivers. Compared to previous studies the enhanced CIS and DIC with dynamic travel speeds affected the waste collection problem in terms of the number of vehicles used, the total distance travelled and the total travel time. However, different settings of speed may give different impacts to the solution. The study reveals that with a setting of dynamic speed between $40 \mathrm{mph}$ and $55 \mathrm{mph}$, DIC is able to reduce two vehicles (from 98 to 96 number of vehicles used), $7.85 \%$ of total distance travelled, and $19.10 \%$ of total travel time.
\end{abstract}

Keywords: Time-dependent vehicle routing, dynamic travel speed, waste collection, heuristics. 


\section{INTRODUCTION}

The vehicle routing problem with time windows (VRPTW) is a combinatorial optimization problem under the variant of vehicle routing problem (VRP). Nowadays, the VRPTW is a popular problem discussed in the literature due to its ability to solve various types of applications. One of the applications of the VRPTW problem is in the area of solid waste management, particularly in the waste collection process. This problem comprises of three important elements: (a) the set of vehicles operating at a single depot, (b) the number of customers to be served and (c) disposal facilities. In collecting waste, vehicles have to start from the depot with empty capacity. Each vehicle has its own capacity limit to accommodate the waste and each customer has their own waste that needs to be collected. Once the vehicles are fully loaded, they need to be emptied at one of the closest disposal facilities before collecting waste from other customers. The same process is carried out until all customers are served. Thus, multiple trips to disposal facilities may occur in order to complete the collection before the vehicle returns to the depot empty for the cleaning process and to prepare for the process of collecting waste the following day. In this problem, each vehicle must arrive at the depot/customer/disposal facility within a given time window.

Previously, most vehicle routing studies assumed that travel times are static (Ichoua et al., 2003). A number of studies have pointed out that the travel time between two collection points does not depend only on the distance travelled but also on several other factors such as road accidents (Kok et al., 2012) traffic jams and road condition (Lecluyse et al., 2009; Toklu et al,. 2013), weather (Kok et al., 2012; Lecluyse et al., 2009), traffic congestion during peak hours (Kok et al., 2012), and crowded carriages during peak hours (Schmöcker et al., 2008).

In this paper, a model of dynamic vehicle travel speed based on vehicle capacity (current weight of the waste) was presented to represent a scenario that occurs in real-life applications. Since this problem involved time windows and time dependence, most researchers in previous literature have referred to it as timedependent VRPTW (TD-VRPTW) (Malandraki \& Daskin, 1992).

In general, TD-VRPTW is a process to find an optimal vehicle route which could reduce the total travelling time starting from the depot, then servicing the customer until there is no customer left to be dealt with and return to the depot as a starting point while considering the travel speed of the vehicle, distance between points, vehicle's capacity, and the time frame itself. The TDVRPTW connects various applications such as courier service (Hill \& Benton, 
1992; Potvin et al., 2006), distribution industry (Ichoua et al., 2003; Kuo et al., 2009) and transportation (Goel \& Gruhn, 2006). Moreover, it is believed that this is the first work that emphasizes the travel speed of vehicles especially in waste collection applications.

The purpose of this paper was to enhance the TD-VRPTW in waste collection applications. This is due to the changes in the vehicle's load (weight of waste that have been collected) and its speed when collecting waste from customers. For example, when the vehicles start and return to the depot with empty capacity, they may travel with the allowed maximum speed, but when the vehicles are fully loaded with collected waste, the speed will be reduced.

This paper enhanced two heuristic algorithms, namely current initial solution (CIS) and different initial customer (DIC). CIS was proposed by Benjamin and Beasley (2010) whereas DIC is an improved algorithm of CIS from Benjamin and Beasley (2013). Previously, both algorithms assumed that vehicles were travelling with a static speed in solving the waste collection benchmark problem. However in this paper, the benchmark problem was solved by assuming that the vehicles were travelling with dynamic speeds when collecting the waste.

This paper believed that the variation in travel speed was due to the changes of the vehicle's load during collecting waste. The benchmark problem was introduced by Kim et al. (2006). It consisted of ten sub problems. Each sub problem involved only one depot. The number of customers to be served, the number of available disposal facilities and the vehicle capacity limit of each sub problem are different.

This paper proposed a vehicle travel speed model which was based on the vehicle's load to enhance the DIC and CIS algorithms in solving the waste collection benchmark problem with dynamic travel speeds. Computational results from DIC and CIS algorithms (static and dynamic travel speeds) were compared in terms of the number of vehicles used, the total distance travelled and the total travel time.

The rest of this paper is organized as follows: Section 2 discusses the literature review related to TD-VRPTW in the waste collection problem. Section 3 presents the vehicle travel speed model that is proposed in this paper to enhance the CIS and DIC algorithms in solving the waste collection VRPTW benchmark problem. Section 4 presents the comparison of the results of CIS and DIC with dynamic speed as well as static speed. The differences of both solutions are discussed at the end of this section. Section 5 provides the conclusion and suggestion for future work. 


\section{LITERATURE REVIEW}

This section consists of two parts. The first part discusses previous studies on time-dependent vehicle routing problem, whereas the second part focuses on the waste collection problem.

\section{Time-dependent Vehicle Routing Problem}

The problem related to time-dependent vehicle travel speed is rarely tackled in the literature because it is critical, difficult to model and hard to solve (Ichoua et al., 2003). In real-life applications, vehicle travel speed cannot be neglected in solving VRPTW problems because when we generate vehicle routes, the arrival time at each point (i.e. customers, depot) needs to be identified. For example, if the vehicle returned to the depot later than expected and violated the time window, the solution proposed could become infeasible.

TD-VRPTW was first proposed by Malandraki and Daskin (1992) where urban congestion was considered in which the travel time was influenced by the distance between nodes (i.e. customers and depot) and the current time. They also found out that assuming the vehicle travel speed was static was far from real-life applications reality. Fluctuations in traffic congestion may affect the speed and give negative impact to the travel time.

A number of articles have considered time-dependent in their research problems. Examples of such articles are Hill and Benton (1992), Ichoua et al. (2003), Fleischmann et al. (2004), Kuo et al. (2009), Cordeau et al. (2014) and Qian and Eglese (2015). In the first study by Hill and Benton (1992) time-dependent travel speed was described in a commercial courier vehicle scheduling system in the metropolitan areas in the United States, and it dealt with data collection and data storage problems. They also stated that most vehicle scheduling had neglected the fact that travel speed depended on the time of the day. Regression was used to solve the problem.

Ichoua et al. (2003) dealt with the "first-in-first-out" role to reduce the travel time and lateness at the customer in the distribution/service industry. A parallel tabu search heuristic algorithm was used to overcome the problem. The solutions of the proposed algorithm were compared in the form of static and dynamic speed situations.

Fleischmann et al. (2004) proposed a framework of travel time based on the actual traffic information system to implement it in the city of Berlin. Donati, Montemanni, Casagrande, Rizzoli, and Gambardella (2008) integrated the 
time-dependent model with the multi ant colony system to solve the vehicle routing problem. They also emphasized the existence of real-time traffic road network in the urban environment in which this condition had greatly affected the routing schedule.

In a study by Kuo et al. (2009) the time-dependent travel speeds, vehicle loading limitation and unloading times were presented in solving VRP. To reduce the total transportation distance and cost, the proposed algorithm was tested in the 3C Distribution Company. Balseiro, Loiseau, and Ramonet (2011) tackled the weakness of the ant colony algorithms which tends to construct infeasible solutions with unrouted customers by integrating it with insertion heuristics algorithms. The time window of the customers and the time dependency between two points depended on the departure time. Other than that, traffic information in the urban area was also considered.

Figliozzi (2012) considered a TD-VRPTW that was inspired from the congestion that occurred in urban areas which emitted major changes in travel speeds especially during peak hours. Iterated route construction and improvement (IRCI) were applied to the problem. Jabali, Van Woensel, and de Kok (2012) considered travel times between customers, fuel consumption and $\mathrm{CO}_{2}$ emissions costs to construct a VRP framework for road freight distribution using tabu search.

Cordeau et al. (2014) proposed a lower and upper bound method for solving asymmetric travelling problems to find the optimality of time-dependent travelling salesman's problem and found out that all arcs shared a similar congestion pattern.

In a study by Qian and Eglese (2015), the vehicle speed that depended on the time of the day was investigated to reduce the usage of fuel emissions by delivery vehicles. Vehicle capacity and time window constraints were also considered. A column-generation-based tabu search was adapted and applied to the problem. They also found that some speed adjustments had to be made to save fuel usage.

Huart, Perron, Caporossi, and Duhamel (2016) integrated variable neighbourhood descend with the column generation procedure to solve TDVRPTW in which the travel time was assumed to change over day according to the real-life urban environment.

Recently, Güner, Murat, and Babu (2017) proposed a dynamic routing within stochastic TSP to determine robust milk-run tours on a stochastic time- 
dependent (STD) network by taking into account the time windows in the STD network to enhance on-time performance. The proposed model also considered real-time traffic data to obtain the information on transportation cost as well as the level of improvement of the delivery services.

Huang, Zhao, Woensel, and Gross (2017) considered path flexibility or pathselection decision in the TDVRP which could minimize the total fuel cost and the vehicle depreciation cost. The proposed model did not only consider vehicle routing decision but also the path-selection decision according to the customers' departure time and the congestion level.

Norouzi, Sadegh-Amalnick, and Tavakkoli-Moghaddan (2017) developed a new mathematical formulation for a green TDVRP which aimed to minimize the total travel time, total travel distance, fuel consumption and the cost of GHG emissions in real-time situations. Traffic congestion during peak hours was considered as well as it might affect the emissions and customer services. A summary of the methods that have been used to solve TDVRP is shown in Table 1.

Table 1

A Summary of Methods that have been used in Solving TDVRP

\begin{tabular}{lll}
\hline \multicolumn{1}{c}{ References } & & \multicolumn{1}{c}{ Methods } \\
\hline Malandraki \& Daskin (1992) & 1. & Mixed integer linear programming \\
& 2. & Nearest neighbour heuristic \\
Hill \& Benton (1992) & 1. & Subjective estimates \\
& 2. & Least square estimates \\
& 3. & Exponential smoothing \\
& 4. & Dynamic vehicle scheduling
\end{tabular}

Ichoua, Gendreau, \& Potvin (2003) A parallel tabu search heuristic.

Fleischmann, Gietz, \& Gnutzmann (2004)
1. Smoothed travel time function

2. Savings algorithm

3. Savings algorithm with insertion

4. Sequential insertion algorithm

5. 2-opt construction algorithm
Donati, Montemanni, Casagrande, Rizzoli, \& Gambardella (2008)
1. Local search procedure

2. Multi ant colony system 


\begin{tabular}{|c|c|}
\hline References & Methods \\
\hline Kuo, Wang \& Chuang (2009) & $\begin{array}{l}\text { 1. Arrival time calculation procedure } \\
\text { 2. Total transportation time procedure } \\
\text { 3. Tabu search algorithm }\end{array}$ \\
\hline Balseiro, Loiseau, \& Ramonet (2011) & $\begin{array}{l}\text { 1. Mixed integer linear programming } \\
\text { 2. Ant colony optimization } \\
\text { 3. Insertion heuristic } \\
\text { 4. Local search procedure }\end{array}$ \\
\hline Figliozzi (2012) & $\begin{array}{l}\text { Iterative route construction and improvement } \\
\text { (IRCI) solution approach }\end{array}$ \\
\hline $\begin{array}{l}\text { Jabali, Van Woensel, \& de Kok } \\
\text { (2012) }\end{array}$ & Tabu search algorithm \\
\hline Cordeau, Ghiani, \& Guerriero (2014) & $\begin{array}{l}\text { 1. Lower and upper bound } \\
\text { 2. Integer linear programming } \\
\text { 3. Branch and cut algorithm }\end{array}$ \\
\hline Qian \& Eglese (2016) & $\begin{array}{l}\text { 1. Column generation technique } \\
\text { 2. Tabu search algorithm }\end{array}$ \\
\hline $\begin{array}{l}\text { Huart, Perron, Caporossi, \& Duhamel } \\
\text { (2016) }\end{array}$ & $\begin{array}{l}\text { 1. A modified Dijkstra algorithm } \\
\text { 2. Column generation technique } \\
\text { 3. Variable neighbourhood descend }\end{array}$ \\
\hline $\begin{array}{l}\text { Huang, Zhao, Woensel, \& Gross } \\
\text { (2017) }\end{array}$ & $\begin{array}{l}\text { 1. Modified Dijkstra's algorithm } \\
\text { 2. Mixed integer linear programming }\end{array}$ \\
\hline Güner, Murat, \& Babu (2017) & Stochastic dynamic programming \\
\hline $\begin{array}{l}\text { Norouzi, Sadegh-Amalnick, \& } \\
\text { Tavakkoli-Moghaddan (2017) }\end{array}$ & Modified particle swarm optimization \\
\hline
\end{tabular}

\section{Waste Collection Vehicle Routing Problem}

All studies discussed in the previous sub-section were not implemented in the waste collection problems. Most previous studies in the waste collection problems assumed that vehicles were travelling with static speed when serving the customers. Such examples of past studies are by Tung and Pinnoi (2000) who described a study on waste collection vehicle routing-scheduling problem in Hanoi; Kim et al. (2006) who conducted a study on waste collection VRPTW with multiple disposal trips and drivers lunch period; Ombuki-Berman et al. (2007) who applied multi-objective genetic algorithms for waste collection 
VRPTW; Benjamin and Beasley $(2010,2013)$ who solved the waste collection VRPTW benchmark problem using metaheuristics; Wy and Kim (2013) who used a large neighbourhood search based iterative heuristic approach for the rollon-rolloff VRPTW, and Fooladi and Fazlollahtabar (2014) who presented a mixed-integer nonlinear programming model for solid waste management (SWM) and reverse supply chain.

Ferreira et al. (2015) developed a decision-support system model by integrating a cellular genetic algorithm with a multi-criteria decision analysis for waste collection route planning. Markov, Varone and Bierlaire (2016) used multiple neighbourhood search heuristic in solving a complex recyclable waste collection problem in Geneva, Switzerland. Vecchi et al. (2016) developed a sequential approach involving two different types of mathematical formulation which were the Binary Integer Linear Programming based on the p-median problem and the Mixed Integer Linear Programming. The author adopted the Hierholzer algorithm as well for the waste collection route optimization problem in Brazil. Alshraideh and Qdais (2016) solved a stochastic medical waste collection problem in Jordan using genetic algorithm which aimed to minimize the total travel distance, transportation cost and emissions. A summary of the methods that have been used to solve waste collection problem with static speed is shown in Table 2 .

\section{Table 2}

A Summary of Methods that have been used to Solve Waste Collection Problems with Static Speed

\begin{tabular}{lll}
\hline \multicolumn{1}{c}{ References } & \multicolumn{1}{c}{ Methods } \\
\hline Tung \& Pinnoi (2000) & 1. & Insertion algorithm \\
& 2. & Sequential route construction \\
& 3. & Parallel route construction \\
& 4. & Or-opt exchange modification \\
& 5. & 2-opt* exchange modification \\
& 6. & Route improvement procedure \\
& & \\
Kim, Kim, \& Sahoo (2006) & 1. An extended insertion algorithm \\
& 2. & CROSS exchange local search method \\
& 3. & Simulated annealing metaheuristic \\
Ombuki-Berman, Runka, \& Hanshar & 1. & Multi-objective optimization and Pareto \\
$(2007)$ & & ranking \\
& 2. & Genetic algorithm \\
& 3. & Weighted sum method
\end{tabular}




\begin{tabular}{|c|c|}
\hline References & Methods \\
\hline Benjamin \& Beasley (2010) & $\begin{array}{l}\text { 1. Initial solution procedure } \\
\text { 2. Local search procedure } \\
\text { 3. Vehicle reduction procedure } \\
\text { 4. Tabu search } \\
\text { 5. Variable neighbourhood search (VNS) } \\
\text { 6. Variable neighbourhood tabu search (VNTS) }\end{array}$ \\
\hline Benjamin \& Beasley (2013) & $\begin{array}{l}\text { 1. Different initial customer procedure } \\
\text { 2. Route improvement procedure } \\
\text { 3. Vehicle reduction procedure } \\
\text { 4. A disposal facility positioning (DFP) } \\
\text { procedure } \\
\text { 5. Change tracking procedure } \\
\text { 6. Reverse order procedure } \\
\text { 7. Tabu search with DFP, change tracking, and } \\
\text { reverse order } \\
\text { 8. VNS with DFP, change tracking, and reverse } \\
\text { order } \\
\text { 9. VNTS with DFP, change tracking, and } \\
\text { reverse order }\end{array}$ \\
\hline Wy \& Kim (2013) & $\begin{array}{l}\text { 1. Large neighbourhood search } \\
\text { 2. Local search improvement procedure }\end{array}$ \\
\hline Fooladi \& Fazlollahtabar (2014) & Mixed integer nonlinear programming \\
\hline Ferreira et al. (2015) & $\begin{array}{l}\text { 1. Cellular genetic algorithm } \\
\text { 2. SMART } \\
\text { 3. ValueFn } \\
\text { 4. Analytic hierarchy process }\end{array}$ \\
\hline Alshraideh \& Qdais (2016) & Genetic algorithm \\
\hline Markov, Varone, \& Bierlaire (2016) & $\begin{array}{l}\text { 1. Mixed integer linear programming } \\
\text { 2. Multiple neighbourhood search }\end{array}$ \\
\hline Vecchi et al. (2016) & $\begin{array}{l}\text { 1. Binary integer linear programming based on } \\
\text { the p-median problem } \\
\text { 2. Mixed integer linear programming } \\
\text { 3. An adapted Hierholzer algorithm }\end{array}$ \\
\hline
\end{tabular}

Table 1 and Table 2 show that heuristic is the most preferred method in solving TDVRP and waste collection problem. This method also has been widely used in solving other real-life problems such as timetabling (Sultan et al., 2004; Abdul-Rahman et al., 2014), text clustering (Mohammed, Yusof \& 
Husni, 2016) and scheduling (Zulkipli, Ibrahim \& Benjamin, 2013; Benjamin, Abdul-Rahman \& Engku Abu Bakar, 2013).

Most of the studies on waste collection problems reported in the literature assumed that the vehicles moved with the same speed when collecting waste from customers (Benjamin \& Beasley, 2013; Benjamin \& Beasley, 2010; Figliozzi, 2012; Ichoua et al., 2003; Kim et al., 2006). Unfortunately, this assumption was irrational, inefficient and did not represent a real-life scenario which leads to suboptimal solutions (Figliozzi, 2012). Without this important factor, the solutions obtained from previous studies might be different in terms of travel time and number of vehicles used. This research enhanced the TDVRPTW problem in waste collection applications.

Time-dependent travel speed is an important factor in solving waste collection VRPTW problems. Thus, this paper investigated the effect of dynamic travel speed of vehicles in which the variation in travel speed was due to the vehicle's load during waste collection. the comparison of the results between the solutions with static travel speed and solutions with dynamic travel speed in terms of the number of vehicles needed, total distance, and time travelled are presented in Section 4.

\section{METHODOLOGY}

This paper enhanced CIS and DIC algorithms from Benjamin and Beasley $(2010,2013)$ by proposing a dynamic vehicle travel speed model, particularly based on the current weight of waste carried by the vehicle in solving waste collection VRPTW benchmark problems adopted from Kim et al. (2006).

\section{Current Initial Solution (CIS) Algorithm}

CIS algorithm constructs an initial solution where each vehicle is fully utilized throughout the day to reduce the total number of vehicles needed. A new vehicle for a new route will be used if the previous vehicle cannot be utilized anymore. CIS consists of five main steps as shown in Figure 1.

\section{Different Initial Customer (DIC) Algorithm}

The DIC algorithm refers to a new set of initial solutions that is constructed with a different initial customer as the first customer to be served from a depot on route 1 . Then, the next customer on the current emerging route is chosen based on the closest customer to the last customer in terms of travel time. DIC consists of six main steps as shown in Figure 2. 


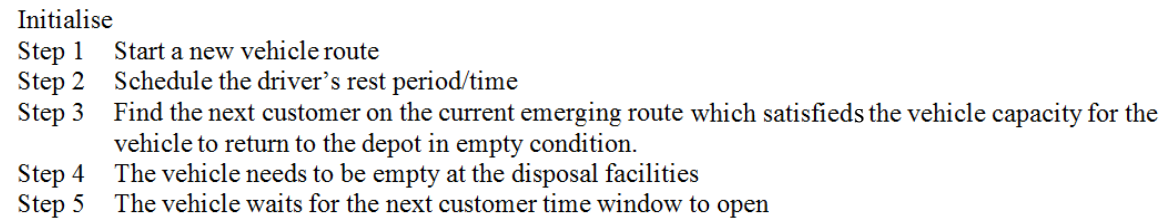

Step 3 Find the next customer on the current emerging route which satisfieds the vehicle capacity for the vehicle to return to the depot in empty condition.

Step 4 The vehicle needs to be empty at the disposal facilities

Step 5 The vehicle waits for the next customer time window to open

Figure 1. Current initial solution (CIS) procedure from Benjamin and Beasley (2010)



Figure 2. Different initial customer (DIC) procedure from Benjamin and Beasley (2013).

Both CIS and DIC are almost similar. DIC consists of an extra step, namely Step 0 where a new set of initial solution is constructed with a different initial customer as the first customer to be served on route 1. Meanwhile for CIS, a new set of initial solution is constructed based on the most nearest customer from the depot. In Step 1, a new vehicle route is constructed. One hour of driver's rest period is scheduled in Step 2. In Step 3, the next customer to be served who satisfies all problem constraints is identified. Step 4 is applied if there are no customers to be served (i.e. violates problem constraints). The vehicle's load is checked; if the vehicle is almost full, then it will travel to the closest disposal facility to empty the waste. In Step 5, the vehicle will travel to the customer whose time window will be opened soon and fulfil other problem constraints. In each step, all variables involved, such as number of customers that have been visited, total vehicle's load, total distance and time travelled, are updated in order to obtain a good feasible solution (e.g. the minimum total distance travelled and the number of vehicles needed to serve all customers).

\section{Vehicle Travel Speed Model}

In this paper, a vehicle travel speed model that was used to enhance CIS and DIC was proposed. The vehicle travel speed model was developed based on the assumption that the vehicle speed would decrease as the load carried by 
the vehicle increases. It was also assumed that the maximum speed of the empty vehicle was $55 \mathrm{mph}$ and the minimum speed of the vehicle when it was fully loaded was $40 \mathrm{mph}$. This assumption was based on a special report from the transportation research board national research council, which is available at http://www.trb.org/main/blurbs/152251.aspx. The proposed model was also based on the capacity of the vehicle used in the ten subproblems. The characteristics of each subproblem are presented in Table 3. The last column in Table 3 shows the capacity of the vehicle used in each subproblem. Since the vehicle capacity used in each subproblem was different, the vehicle travel speed model for each sub problem became varied.

Table 3

Characteristics of Waste Collection VRPTW Benchmark Problem

\begin{tabular}{cccc}
\hline Subproblem & $\begin{array}{c}\text { Number of } \\
\text { customers }\end{array}$ & $\begin{array}{c}\text { Number of } \\
\text { disposal facilities }\end{array}$ & $\begin{array}{c}\text { Capacity of a } \\
\text { vehicle (ton) }\end{array}$ \\
\hline 102 & 99 & 2 & 280 \\
277 & 275 & 1 & 200 \\
335 & 330 & 4 & 243 \\
444 & 442 & 1 & 200 \\
804 & 784 & 19 & 280 \\
1051 & 1048 & 2 & 200 \\
1351 & 1347 & 3 & 255 \\
1599 & 1596 & 2 & 280 \\
1932 & 1927 & 4 & 462 \\
2100 & 2092 & 7 & 462 \\
\hline Total & 9940 & & \\
\hline
\end{tabular}

This study used the general linear equation, $y=m x+c$ to develop the vehicle travel speed model where $y$ is the vehicle travel speed, $x$ is the weight of waste carried by the vehicle, $m$ is the gradient, and $c$ is the $y$-intercept (i.e. vehicle speed when the vehicle is empty). The example of vehicle travel speed model for sub problem 102 is illustrated in Figure 3.

Based on Figure 3, the vehicle travel speed model for subproblem 102 is $y$ $=-0.0536 x+55$ where $m=-0.0536$. The value of $m$ was calculated using the gradient formula as shown in Equation (1).

$$
\begin{aligned}
m & =\frac{y_{2}-y_{1}}{x_{2}-x_{1}} \\
& =\frac{55-40}{0-280}=-\mathbf{0 . 0 5 3 6}
\end{aligned}
$$




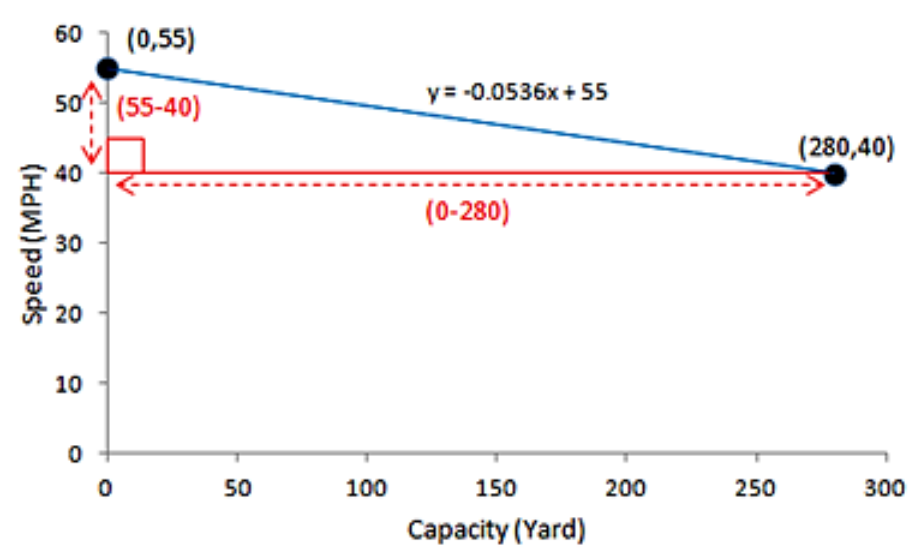

Figure 3. Vehicle travel speed model for sub problem 102.

The negative value of $m$ indicates the negative relationship between capacity and speed (i.e. when the vehicle capacity increases by 1 ton of waste, the vehicle speed decreases by $0.0536 \mathrm{mph}$ ), and $c=55$ is the intercept on the $y$-axis (i.e. when the vehicle is empty, $x=0$, vehicle speed is $55 \mathrm{mph}$ ). The vehicle travel speed model for each subproblem is presented in Table 4.

Table 4

Vehicle Travel Speed Model

\begin{tabular}{cc}
\hline Subproblem & Linear equation \\
\hline 102 & $y=-0.0536 x+55$ \\
277 & $y=-0.075 x+55$ \\
335 & $y=-0.0617 x+55$ \\
444 & $y=-0.075 x+55$ \\
804 & $y=-0.0536 x+55$ \\
1051 & $y=-0.075 x+55$ \\
1351 & $y=-0.0588 x+55$ \\
1599 & $y=-0.0536 x+55$ \\
1932 & $y=-0.0325 x+55$ \\
2100 & $y=-0.0325 x+55$ \\
\hline
\end{tabular}




\section{Modification of CIS and DIC Algorithms with Dynamic Travel Speeds}

Previously in Benjamin and Beasley $(2010,2013)$, the vehicle travel time was calculated using Equation (2).

$$
t_{r j}=d_{r j}\left(\frac{3600}{40}\right)
$$

where $d_{r j}$ is the distance between $r$ and $j$ ( $r$ and $j$ can be a customer, depot or disposal facility) and 40 was set as the static speed (40 mph).

All the travel times mentioned were calculated using $d_{i j}(3600 /-0.0536 x+5)$ where $d_{i j}$ is the distance from customer $i$ to customer $j$. The symbol $x$ represents the current weight of waste carried by the vehicle and it was assumed that the vehicle speed changed according to the current vehicle capacity. However, in this study, the vehicle travel time between $r$ and $j\left(t_{r j}\right)$ was calculated using a similar equation as in Equation (2) but the static speed (40) was replaced with a linear equation of the dynamic speed model which can be obtained in Table 4. After the substitution, the new equation formed is shown as follows (this is an example for subproblem 102):

$$
t_{r j}=d_{r j}(3600 /-0.0536 x+55)
$$

where $x$ is the current load on the vehicle. Thus, in order to enhance CIS and DIC with dynamic travel speeds, Step 1, Step 3, Step 4, and Step 5 were modified. As an example, the modifications of CIS and DIC with the proposed vehicle speed model for sub problem 102 are highlighted in Figures 4, 5, 6 and 7.

$$
\begin{aligned}
& \text { if }|B| \neq 0 \text { so there are still customers to be dealt with then: } \\
& \text { start a new vehicle route at time } E_{0}, \text { when the depot opens } \\
& \begin{array}{ll}
T=E_{0} & T \text { is the current time } \\
S_{\text {total }}=0 & S_{\text {total }} \text { is the total number of customers the vehicle has visited } \\
Q_{\text {total }}=0 & Q_{\text {total }} \text { is the total load the vehicle has dealt with } \\
Q_{\text {current }}=0 & Q_{\text {current }} \text { is the current load on the vehicle } \\
r=0 & \text { is the customer at the end of the current emerging } \\
& \text { vehicle route } \\
& \text { rest is one if the vehicle has had its rest period, else zero } \\
t_{0 r}=d_{0 r} *\left(\frac{3600}{\left(-0.0536^{*} Q_{\text {curent }}\right)+55}\right) & t_{0 r}, \text { travel time from depot to the customer } r \text { is } \\
& \text { calculated using vehicle travel speed model, } \\
& d_{0 r} \text { is a distance from depot to the customer } r
\end{array}
\end{aligned}
$$

All customers have been dealt with so stop

Figure 4. Step 1 of CIS and DIC with dynamic travel speeds. 


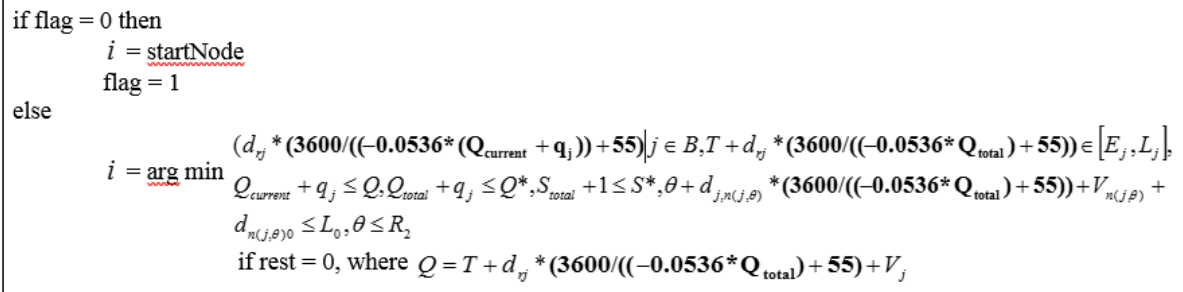

Figure 5. Step 3 of CIS and DIC with dynamic travel speeds.

if vehicle is not empty $\left(Q_{\text {current }}>0\right)$ then:

the vehicle travels to its nearest disposal facility $n(r, T)$ to be emptied

$$
\begin{aligned}
& T=T+d_{r, n(r, T)} *\left(3600 /\left(\left(-0.0536 * \mathbf{Q}_{\text {total }}\right)+55\right)+V_{n(r, T)}\right. \\
& r=n(r, T) \\
& Q_{\text {current }}=0
\end{aligned}
$$

update the current time with dynamic travel speeds update the end of the route update the current vehicle load

go to step 2

Figure 6. Step 4 of CIS and DIC with dynamic travel speeds.

Find a customer whose time window will open as soon as possible:

$$
\begin{aligned}
& {\left[E_{j} \mid j \in B, T+d_{r j} *\left(\mathbf{3 6 0 0} /\left(-\mathbf{0 . 0 5 3 6} \mathbf{Q}_{\text {current }}\right)+\mathbf{5 5}<E_{j}, Q_{\text {current }}+q_{j} \leq Q,\right.\right.} \\
i=\arg \min & Q_{\text {total }}+q_{j} \leq Q^{*}, S_{\text {total }}+1 \leq S^{*}, \theta+d_{j, n(j, \theta)} *\left(\mathbf{3 6 0 0} /\left(\left(-\mathbf{0 . 0 5 3 6} \mathbf{Q}_{\text {total }}\right)+\mathbf{5 5}\right)\right. \\
& \left.+V_{n(j, \theta)} \leq L_{0}, \theta \leq R_{2} \text { if rest }=0, \text { where } \theta=E_{j}+V_{j}\right],
\end{aligned}
$$

if there is a customer $i$ is satisfying the above expression then:

$$
\text { the vehicle travels to } i \text {, waits until } E_{i} \text {, and services the customer }
$$$$
T=E_{i}+V_{i} \quad \text { update the current time }
$$$$
j=i \quad \text { update the current customer at the end of the route }
$$$$
Q_{\text {current }}=Q_{\text {current }}+q_{i} \quad \text { update the current vehicle load }
$$$$
Q_{\text {total }}=Q_{\text {total }}+q_{i} \quad \text { update the daily vehicle load }
$$$$
s_{\text {total }}=s_{\text {total }}+1 \quad \text { update the total number of customers visited }
$$$$
B=B-\{i\} \quad \text { update the set of customers } B \text { by removing } i \text { from it }
$$$$
t_{r j}=d_{r j} *\left(\frac{3600}{\left(-0.0536^{*} \mathbf{Q}_{\text {current }}\right)+55}\right) \quad t_{r j} \text {, travel time from customer } r \text { to the customer } j \text { is }
$$

calculated using vehicle travel speed model,

$d_{r j}$ is a distance from customer $r$ to the customer $j$

Go to step 2

the vehicle travels back to the depot (as it is empty it does not need to visit a disposal facility first) and end if for a new vehicle to be used go to step 1

Figure 7. Step 5 of CIS and DIC with dynamic travel speeds. 


\section{RESULTS}

In this section, computational results of CIS and DIC with dynamic travel speeds for waste VRPTW benchmark problem adopted from Kim et al. (2006) are presented. Both algorithms are implemented in $\mathrm{C}++$ language and run on an Intel ${ }^{\circledR}$ Core TM i7-3770 CPU @ 3.40GHz with 8.00GB memory. Since no complete solution using CIS and DIC was reported in Benjamin and Beasley $(2010,2013)$ or Benjamin (2011), the algorithms were rerun in order to make comparisons and the corresponding authors have checked and approved the reliability of the solutions derived from the analysis.

Table 5 shows the comparison of the results between CIS and DIC with dynamic travel speeds and a static travel speed $(40 \mathrm{mph})$ from Benjamin and Beasley $(2010,2013)$ and Benjamin (2011). The last two columns in Table 5 show the percentage of improvement in total distance and total travel time when compared to the solutions obtained from CIS and DIC with a static travel speed.

The sixth column in Table 5 shows the improvement in distance travelled over the DIC with a static speed solution. The positive percentage indicates that the total travel distance of vehicles was reduced compared to the solutions obtained from CIS or DIC with a static speed. The percentage was computed using the following equation:

$\%$ of improvement in distance $=\left(\frac{\text { distance from CIS or DIC with a static speed }- \text { distance from CIS or DIC with dynamic speeds }}{\text { distance from CIS or DIC with a static speed }}\right) 100$

The result shows that DIC with dynamic speeds for subproblem 335 gave the highest reduction $(22.23 \%)$ in the total distance travelled, whereas, the negative percentage for subproblems 102 and 804 indicate that the total distance travelled increased about $7.40 \%$ and $0.90 \%$, respectively over the DIC with a static speed.

The last column in Table 5 shows the improvement in total time travelled over CIS and DIC with static speed solutions. In this column, the positive percentage also indicates that the total travel time of vehicles was reduced compared to the solutions obtained from CIS and DIC with a static speed. The percentage was computed using the following equation:

$\%$ of improvement in travel time $=\left(\frac{\text { travel time from CIS or DIC with a static speed - travel time from CIS or DIC with dynamic speeds }}{\text { fravel time from CIS or DIC with a static speed }}\right) 100$

Based on the results, DIC with dynamic speeds produced better total travel time for all subproblems compared to DIC with a static speed. Subproblem 335 showed the highest reduction $(36.58 \%)$ in the total travel time. 
Overall, Table 5 shows that DIC with dynamic travel speeds produced better solutions than other algorithms in terms of the number of vehicles needed, total travel distance and total travel time (as highlighted in Table 5). The comparison of the results show that the total number of vehicles used for solving the ten sub problems using the DIC with dynamic speeds was reduced by two compared to DIC with a static speed (from 98 to 96 number of vehicles used). Total travel distance and total travel time also decreased by about $7.85 \%$ and $19.10 \%$, respectively.

When vehicles travel with dynamic speeds, there would be a possibility that each vehicle is able to visit more customers per day. Thus, fewer vehicles are needed to serve all customers. In this case, subproblems 1932 and 2100 used one vehicle less compared to the solution with static speed.

\section{Table 5}

Comparison of the results between CIS and DIC (Static Speed and Dynamic Speed)

\begin{tabular}{|c|c|c|c|c|c|c|}
\hline Subproblem & Algorithms & $\begin{array}{c}\begin{array}{c}\text { Number } \\
\text { of }\end{array} \\
\text { vehicles } \\
\text { used }\end{array}$ & $\begin{array}{c}\text { Total } \\
\text { distance } \\
\text { (mile) }\end{array}$ & $\begin{array}{c}\text { Total } \\
\text { travel } \\
\text { time (sec) }\end{array}$ & $\begin{array}{c}\% \\
\text { improvement } \\
\text { in distance }\end{array}$ & $\begin{array}{c}\% \\
\text { improvement } \\
\text { in travel time }\end{array}$ \\
\hline \multirow[t]{4}{*}{102} & CIS-Static & 3 & 206.80 & 18611.8 & \multirow[t]{2}{*}{2.82} & \multirow[t]{2}{*}{18.99} \\
\hline & CIS-Dynamic & 3 & 200.98 & 15076.5 & & \\
\hline & DIC-Static & 3 & 184.31 & 16587.7 & \multirow[t]{2}{*}{-7.40} & \multirow[t]{2}{*}{9.53} \\
\hline & $\begin{array}{c}\text { DIC- } \\
\text { Dynamic }\end{array}$ & 3 & 197.94 & 15007.2 & & \\
\hline \multirow[t]{5}{*}{277} & CIS-Static & 3 & 473.83 & 42644.2 & \multirow[t]{2}{*}{-6.66} & \multirow[t]{2}{*}{15.54} \\
\hline & CIS-Dynamic & 3 & 505.39 & 39786.8 & & \\
\hline & DIC-Static & 3 & 473.83 & 42644.2 & \multirow[t]{3}{*}{4.17} & \multirow[t]{2}{*}{15.54} \\
\hline & DIC- & 3 & 454.09 & 36018.4 & & \\
\hline & & & & & & \\
\hline \multirow[t]{5}{*}{335} & CIS-Static & 6 & 213.28 & 19194.9 & \multirow[t]{2}{*}{20.83} & \multirow[t]{2}{*}{34.64} \\
\hline & CIS-Dynamic & 6 & 168.85 & 12545.9 & & \\
\hline & DIC-Static & 6 & 200.25 & 18022.8 & \multirow[t]{3}{*}{22.23} & \multirow[t]{3}{*}{36.58} \\
\hline & DIC- & 6 & 155.73 & 11429.6 & & \\
\hline & Dynamic & & & & & \\
\hline \multirow[t]{4}{*}{444} & CIS-Static & 11 & 92.93 & 8363.99 & \multirow[t]{2}{*}{15.44} & \multirow[t]{2}{*}{27.17} \\
\hline & CIS-Dynamic & 11 & 78.58 & 6091.75 & & \\
\hline & DIC-Static & 11 & 89.12 & 8020.58 & \multirow[t]{2}{*}{14.07} & \multirow[t]{2}{*}{26.61} \\
\hline & $\begin{array}{c}\text { DIC- } \\
\text { Dynamic }\end{array}$ & 11 & 76.58 & $\mathbf{5 8 8 6 . 2 7}$ & & \\
\hline
\end{tabular}




\begin{tabular}{|c|c|c|c|c|c|c|}
\hline Subproblem & Algorithms & $\begin{array}{c}\text { Number } \\
\text { of } \\
\text { vehicles } \\
\text { used }\end{array}$ & $\begin{array}{c}\text { Total } \\
\text { distance } \\
\text { (mile) }\end{array}$ & $\begin{array}{c}\text { Total } \\
\text { travel } \\
\text { time (sec) }\end{array}$ & $\begin{array}{c}\% \\
\text { improvement } \\
\text { in distance }\end{array}$ & $\begin{array}{c}\% \\
\text { improvement } \\
\text { in travel time }\end{array}$ \\
\hline \multirow[t]{2}{*}{804} & $\begin{array}{c}\text { CIS-Static } \\
\text { CIS-Dynamic }\end{array}$ & $\begin{array}{l}6 \\
5\end{array}$ & $\begin{array}{l}\mathbf{8 6 3 . 3 3} \\
796.81\end{array}$ & $\begin{array}{l}77699.6 \\
\mathbf{6 2 0 2 4 . 8}\end{array}$ & 7.71 & 20.17 \\
\hline & $\begin{array}{c}\text { DIC-Static } \\
\text { DIC- } \\
\text { Dynamic }\end{array}$ & $\begin{array}{l}5 \\
5\end{array}$ & $\begin{array}{l}723.50 \\
730.05\end{array}$ & $\begin{array}{l}65115.3 \\
\mathbf{5 7 3 7 7 . 1}\end{array}$ & -0.90 & 11.88 \\
\hline \multirow[t]{2}{*}{1051} & $\begin{array}{c}\text { CIS-Static } \\
\text { CIS-Dynamic }\end{array}$ & $\begin{array}{l}17 \\
17\end{array}$ & $\begin{array}{l}2645.07 \\
2437.07\end{array}$ & $\begin{array}{l}238057 \\
197450\end{array}$ & 7.86 & 17.06 \\
\hline & $\begin{array}{c}\text { DIC-Static } \\
\text { DIC- } \\
\text { Dynamic }\end{array}$ & $\begin{array}{l}17 \\
17\end{array}$ & $\begin{array}{l}2550.92 \\
\mathbf{2 2 4 5 . 9 7}\end{array}$ & $\begin{array}{l}229583 \\
\mathbf{1 8 7 1 1 2}\end{array}$ & 11.95 & 18.50 \\
\hline \multirow[t]{2}{*}{1351} & $\begin{array}{l}\text { CIS-Static } \\
\text { CIS-Dynamic }\end{array}$ & $\begin{array}{l}8 \\
8\end{array}$ & $\begin{array}{c}984.3 \\
860.28\end{array}$ & $\begin{array}{l}88586.9 \\
66749.3\end{array}$ & 12.60 & 24.65 \\
\hline & $\begin{array}{c}\text { DIC-Static } \\
\text { DIC- } \\
\text { Dynamic }\end{array}$ & $\begin{array}{l}8 \\
8\end{array}$ & $\begin{array}{l}914.91 \\
799.67\end{array}$ & $\begin{array}{l}82341.9 \\
\mathbf{6 3 3 5 6 . 7}\end{array}$ & 12.60 & 23.06 \\
\hline \multirow[t]{2}{*}{1599} & $\begin{array}{l}\text { CIS-Static } \\
\text { CIS-Dynamic }\end{array}$ & $\begin{array}{l}14 \\
13\end{array}$ & $\begin{array}{l}1578.13 \\
\mathbf{1 4 1 0 . 6 5}\end{array}$ & $\begin{array}{l}142032 \\
\mathbf{1 0 8 2 5 3}\end{array}$ & 10.61 & 23.78 \\
\hline & $\begin{array}{c}\text { DIC-Static } \\
\text { DIC- } \\
\text { Dynamic }\end{array}$ & $\begin{array}{l}13 \\
13\end{array}$ & $\begin{array}{l}1378.01 \\
\mathbf{1 3 0 4 . 4 5}\end{array}$ & $\begin{array}{l}124021 \\
\mathbf{1 0 0 9 5 3}\end{array}$ & 5.34 & 18.60 \\
\hline \multirow[t]{2}{*}{1932} & $\begin{array}{c}\text { CIS-Static } \\
\text { CIS-Dynamic }\end{array}$ & $\begin{array}{l}16 \\
16\end{array}$ & $\begin{array}{l}1346.11 \\
1406.77\end{array}$ & $\begin{array}{l}121150 \\
105945\end{array}$ & -4.51 & 12.55 \\
\hline & $\begin{array}{c}\text { DIC-Static } \\
\text { DIC- } \\
\text { Dynamic }\end{array}$ & $\begin{array}{l}16 \\
\mathbf{1 5}\end{array}$ & $\begin{array}{l}1282.32 \\
\mathbf{1 2 4 7 . 1 9}\end{array}$ & $\begin{array}{l}115409 \\
\mathbf{9 6 6 0 0 . 1}\end{array}$ & 2.74 & 16.30 \\
\hline \multirow[t]{2}{*}{2100} & $\begin{array}{l}\text { CIS-Static } \\
\text { CIS-Dynamic }\end{array}$ & $\begin{array}{l}16 \\
16\end{array}$ & $\begin{array}{l}1823.59 \\
\mathbf{1 8 3 8 . 5 9}\end{array}$ & $\begin{array}{l}164123 \\
\mathbf{1 4 0 3 8 5}\end{array}$ & -0.82 & 14.46 \\
\hline & $\begin{array}{c}\text { DIC-Static } \\
\text { DIC- } \\
\text { Dynamic }\end{array}$ & $\begin{array}{l}16 \\
15\end{array}$ & $\begin{array}{l}1773.53 \\
\mathbf{1 6 0 7 . 6 1}\end{array}$ & $\begin{array}{l}159618 \\
\mathbf{1 2 3 1 3 2}\end{array}$ & 9.36 & 22.86 \\
\hline \multirow[t]{2}{*}{ Total } & $\begin{array}{l}\text { CIS-Static } \\
\text { CIS-Dynamic }\end{array}$ & $\begin{array}{c}100 \\
98\end{array}$ & & & 5.12 & 18.05 \\
\hline & $\begin{array}{l}\text { DIC-Static } \\
\text { DIC- } \\
\text { Dynamic }\end{array}$ & $\begin{array}{l}98 \\
96\end{array}$ & $\begin{array}{l}9570.70 \\
\mathbf{8 8 1 9 . 2 8}\end{array}$ & & 7.85 & 19.10 \\
\hline
\end{tabular}

\section{CONCLUSION}

In this paper, a vehicle travel speed model was proposed to enhance two heuristic algorithms, namely current initial solution (CIS) and different initial customer (DIC) algorithms from Benjamin and Beasley $(2010,2013)$. Both algorithms were used to solve a waste collection benchmark problem by assuming that 
the vehicles were travelling with dynamic speeds when collecting waste. This paper also assumed that the variation in travel speed was due to the changes of the vehicle's load during collecting waste. Previously, Benjamin and Beasley $(2010,2013)$ solved the benchmark problem with a static travel speed of 40 mph. Thus in this paper, computational results from DIC and CIS algorithms (static and dynamic travel speeds) were compared.

The comparison of the results of both algorithms show that dynamic travel speeds of vehicles in a waste collection problem greatly influenced the total travel time, total travel distance and the number of vehicles needed. DIC with dynamic speeds produced better solutions than CIS with static and dynamic speeds, and also DIC with a static speed in solving the waste collection benchmark problem. With the application of DIC with dynamic speeds, two less vehicles were used, $7.85 \%$ less distance travelled, and $19.10 \%$ less travel time compared to the solution obtained from DIC with a static speed. However, it should be known that different settings of speed may give different impacts to the solution. In this paper, with a setting of dynamic speed between $40 \mathrm{mph}$ to $55 \mathrm{mph}$, two less vehicles were used, $7.85 \%$ less distance travelled, and $19.10 \%$ less travel time. In the near future, we would like to conduct a similar research by testing the DIC with dynamic travel speeds on a real data set as it would be interesting to compare it with the existing waste collection schedule used by the waste management corporation.

\section{ACKNOWLEDGEMENTS}

The authors are grateful to Universiti Utara Malaysia (UUM) and the Ministry of Higher Education (MOHE) Malaysia for supporting the research funding under the Research Acculturation Grant Scheme (RAGS), code number 12727 to carry out this research work. We would also like to express our thanks to Aida Mauziah Benjamin, the corresponding author of Benjamin and Beasley (2010, 2013) for approving the DIC with a static speed solution that we reran once again in order to obtain the full solution that could not be found in Benjamin and Beasley $(2010,2013)$ and Benjamin (2011) for making comparisons with the solutions from DIC with the dynamic speeds algorithm.

\section{REFERENCES}

Abdul-Rahman, S., Sobri, N.S., Omar, M.F., Benjamin, A.M., \& Ramli, R. (2014). Graph coloring heuristics for solving examination timetabling problem at Universiti Utara Malaysia. AIP Conference Proceedings, 1635(1), 491-496. 
Alshraideh, H., \& Qdais, H. A. (2016). Stochastic modeling and optimization of medical waste collection in Northern Jordan. Journal of Material Cycles and Waste Management, 1-11. http://doi.org/10.1007/s10163016-0474-3

Balseiro, S. R., Loiseau, I., \& Ramonet, J. (2011). An ant colony algorithm hybridized with insertion heuristics for the time dependent vehicle routing problem with time windows. Computers \& Operations Research, 38(6), 954-966. http://doi.org/10.1016/j.cor.2010.10.011

Benjamin, A. M., \& Beasley, J. E. (2010). Metaheuristics for the waste collection vehicle routing problem with time windows, driver rest period and multiple disposal facilities. Computers \& Operations Research, 37(37), 2270-2280. doi: 10.1016/j.cor.2010.03.019

Benjamin, A. M. (2011). Metaheuristics for the waste collection vehicle routing problem with time windows (Ph.D Thesis). Retrieved from http://bura.brunel.ac.uk/handle/2438/5254

Benjamin, A. M., \& Beasley, J. E. (2013). Metaheuristics with disposal facility positioning for the waste collection VRP with time windows. Optimization Letters, 7(7), 1433-1449. doi:10.1007/s11590-012-05496

Benjamin, A.M., Abdul-Rahman, S., \& Engku Abu Bakar, E.M.N. (2013). Heuristic technique for tour package models. Proceedings of the International Conference on Information, Operations Management and Statistics. 1-8.

Cordeau, J. F., Ghiani, G., \& Guerriero, E. (2014). Analysis and branch-andcut algorithm for the time-dependent travelling salesman problem. Transportation Science, 48(1), 46-58. doi:10.1287/trsc.1120.0449

Donati, A. V., Montemanni, R., Casagrande, N., Rizzoli, A. E., \& Gambardella, L. M. (2008). Time dependent vehicle routing problem with a multi ant colony system. European Journal of Operational Research, 185(3), 1174-1191. doi: 10.1016/j.ejor.2006.06.047

Figliozzi, M.A. (2012). The time dependent vehicle routing problem with time windows: Benchmark problems, an efficient solution algorithm, and solution characteristics. Transportation Research Part E: Logistics and Transportation Review, 48(3), 616-636. doi:10.1016/j.tre.2011.11.006 
Ferreira, J. A., Costa, M., Tereso, A., \& Oliveira, J. A. (2015). A multi-criteria decision support system for a routing problem in waste collection. In Gaspar-Cunha, A., Antunes, C. H., Coello, C. C. (Eds.), Evolutionary Multi-Criterion Optimization (pp. 388-402). Springer International Publishing.

Fleischmann, B., Gietz, M., \& Gnutzmann, S. (2004). Time-varying travel times in vehicle routing. Transportation Science, 38(2), 160-173.

Fooladi, S., \& Fazlollahtabar, H. (2014). Waste collection vehicle routing problem considering similarity pattern of trash can and garbage unloading. International Journal of Modern Management and Foresight, 1(7), 245-254.

Goel, A., \& Gruhn, V. (2006). Solving a dynamic real-life vehicle routing problem. In Haasis, H. D., Kopfer, I. H., Schonberger, J. (Eds.), Operations Research Proceedings 2005 (pp. 367-372). Springer Berlin Heidelberg.

Güner, A. R., Murat, A., \& Babu, R. (2017). Dynamic routing for milkrun tours with time windows in stochastic time-dependent networks. Transportation Research Part E, 97, 251-267. doi: 10.1016/j. tre.2016.10.014

Hill, A. V., \& Benton, W. C. (1992). Modelling intra-city time-dependent travel speeds for vehicle scheduling problems. Journal of the Operational Research Society, 43(4), 343-351. doi: 10.2307/2583157

Huang, Y., Zhao, L., Woensel, T. Van, \& Gross, J. (2017). Time-dependent vehicle routing problem with path flexibility. Transportation Research Part B, 95, 169-195. http://doi.org/10.1016/j.trb.2016.10.013

Huart, V., Perron, S., Caporossi, G., \& Duhamel, C. (2016). A heuristic for the time-dependent vehicle routing problem with time windows. In Computational Management Science (pp. 73-78). Springer International Publishing. http://doi.org/10.1007/978-3-319-20430-7

Ichoua, S., Gendreau, M., \& Potvin, J. Y. (2003). Vehicle dispatching with time-dependent travel times. European Journal of Operational Research, 144(2), 379-396. doi: 10.1016/S0377-2217(02)00147-9

Jabali, O., Van Woensel, T., \& de Kok, A. G. (2012). Analysis of travel times and CO 2 emissions in time-dependent vehicle routing. Production 
and Operation Management, 21(6), 1060-1074. http://doi.org/10.1111/ j.1937-5956.2012.01338.x

Kim, B. I., Kim, S., \& Sahoo, S. (2006). Waste collection vehicle routing problem with time windows. Computers \& Operations Research, 33(12), 3624-3642. doi: 10.1016/j.cor.2005.02.045

Kok, A. L., Hans, E. W., \& Schutten, J. M. J. (2012). Vehicle routing under time-dependent travel times: The impact of congestion avoidance. Computers \& Operations Research, 39(5), 910-918. doi: 10.1016/j. cor.2011.05.027

Kuo, Y., Wang, C. C., \& Chuang, P. Y. (2009). Optimizing goods assignment and the vehicle routing problem with time-dependent travel speeds. Computers \& Industrial Engineering, 57(4), 1385-1392. doi: 10.1016/j. cie.2009.07.006

Lecluyse, C., Woensel, T., \& Peremans, H. (2009). Vehicle routing with stochastic time-dependent travel times. A Quarterly Journal of Operation Research, 7(4), 363-377. doi: 10.1007/s10288-009-0097-9

Malandraki, C., \& Daskin, M. S. (1992). Time dependent vehicle routing problems: Formulations, properties and heuristic algorithms. Transportation Science, 26, 185-200. doi: 10.1287/trsc.26.3.185

Markov, I., Varone, S., \& Bierlaire, M. (2016). Integrating a heterogeneous fixed fleet and a flexible assignment of destination depots in the waste collection VRP with intermediate facilities. Transportation Research Part B: Methodological, 84, 256-273. http://doi.org/10.1016/j. trb.2015.12.004

Mohammed, A.J., Yusof, Y., \& Husni, H. (2016). GF-CLUST: A natureinspired algorithm for automatic text clustering. Journal of Information and Communication Technology, 15(1), 57-81. Retrieved from http:// www.jict.uum.edu.my/index.php

Norouzi, N., Sadegh-Amalnick, M., \& Tavakkoli-Moghaddan, R. (2017). Modified particle swarm optimization in a time-dependent vehicle routing problem: minimizing fuel consumption. Optimization Letters, 11(1), 121-134. http://doi.org/10.1007/s11590-015-0996-y

Ombuki-Berman, B. M., Runka, A., \& Hanshar, F. (2007). Waste collection vehicle routing problem with time windows using multi-objective 
genetic algorithms. Proceedings of the Third IASTED International Conference on Computational Intelligence, (ACTA Press Anaheim, CA, USA), 91-97.

Potvin, J. Y., Xu, Y., \& Benyahia, I. (2006). Vehicle routing and scheduling with dynamic travel times. Computers \& Operations Research, 33(4), 1129-1137. doi: 10.1016/j.cor.2004.09.015

Qian, J., \& Eglese, R. (2016). Fuel emissions optimization in vehicle routing problems with time-varying speeds. European Journal of Operational Research, 248(3), 840-848. doi: 10.1016/j.ejor.2015.09.009

Schmöcker, J. D., Bell, M. G. H., \& Kurauchi, F. (2008). A quasi-dynamic capacity constrained frequency-based transit assignment model. Transportation Research Part B: Methodological, 42(10), 925-945. doi: 10.1016/j.trb.2008.02.001

Sultan, A.B.M., Mahmod, R., Sulaiman, M.N., \& Bakar, M.R.A. (2004). A genetic algorithm approach for timetabling problem: The time group strategy. Journal of Information and Communication Technology, 3(2), 1-14. Retrieved from http://www.jict.uum.edu.my/index.php

Toklu, N. E., Montemanni, R., \& Gambardella, L. M. (2013). An ant colony system for the capacitated vehicle routing problem with uncertain travel costs. In IEEE Symposium on Swarm Intelligence (SIS), 32-39.

Tung, D. V., \& Pinnoi, A. (2000). Vehicle routing-scheduling for waste collection in Hanoi. European Journal of Operational Research, 125(3), 449-468. doi: 10.1016/S0377-2217(99)00408-7

Vecchi, T. P. B., Surco, D. F., Constantino, A. A., Steiner, M. T. A., Jorge, L. M. M., Ravagnani, M. A. S. S., \& Paraiso, P. R. (2016). A sequential approach for the optimization of truck routes for solidWaste collection. Process Safety and Environmental Protection, 102, 238-250. http://doi. org/10.1016/j.psep.2016.03.014

Wy, J., \& Kim, B. I. (2013). A hybrid metaheuristic approach for the rollonrolloff vehicle routing problem. Computers \& Operations Research, 40(8), 1947-1952. doi: 10.1016/j.cor.2013.03.006

Zulkipli, F., Ibrahim, H., \& Benjamin, A.M. (2013). Optimization capacity planning problem on conference scheduling. IEEE of the Business Engineering and Industrial Applications Colloquium.911-915. doi: 10.1109/BEIAC.2013.6560270 
